\title{
O Brasil se tornará, em 2015, o principal produtor de conhecimento em Odontologia no mundo
}

Analistas econômicos, técnicos do Banco Mundial e acadêmicos do meio concordam que o Brasil deverá assumir a posição de $5^{\mathrm{a}}$ economia do mundo em um prazo relativamente curto. Aqueles afeitos à ciência podem até se espantar com o crescimento econômico, mas não com a forma de se averiguar e projetar essa posição do país. Modelos estatísticos de "regressão", que no vernáculo da área é sinônimo de "previsão", são utilizados para esse fim. As séries históricas são analisadas e cenários futuros são estimados.

Em verdade, essa é uma ferramenta recorrente em diferentes estudos publicados nas páginas do DPJO. Em ciência, é fundamental em certos casos analisar dados para desenvolver modelos preditivos. Esses modelos são utilizados como parâmetro para prever resultados, classificar casos e entender a dificuldade de certos tratamentos.

As estatísticas também são utilizadas para avaliar a quantidade e a qualidade da produção científica dos países e especialidades. Um dos bancos de dados disponíveis para consulta com esse fim é o da SCOPUS ${ }^{1}$ e, recentemente, fiz uma análise das informações disponibilizadas por ele. Esse exercício incluiu avaliar as estatísticas descritivas da produção científica dos principais países produtores de conhecimento na Odontologia. Avaliei duas vertentes: a produção de todas as áreas e a da Ortodontia isoladamente.
Em 1996, primeiro ano constante nessa base de dados, o Brasil estava em $17^{\circ}$ lugar no ranking de número de artigos produzidos em Odontologia. Todavia, quando avaliamos a produção total entre 1996 e 2009, saltamos para o $4^{\circ}$ lugar. O ano de 2009 é o mais recente da lista da SCOPUS. Entretanto, o mais interessante é o que ocorre quando detalhamos um pouco mais essa pesquisa. Se apenas o ano de 2009 é submetido à análise, nosso país se encontra em $2^{\circ}$ lugar no número de artigos produzidos, atrás apenas dos EUA.

Quando avaliamos a especialidade de Ortodontia de maneira isolada, os dados ficam ainda mais motivantes. Ao longo de todo o período de 1996-2009, nosso país se encontra em $2^{\circ}$ lugar no ranking de publicações na área. Mas quando apenas os anos de 2008 e 2009 são analisados, estamos - pasmem - em $1^{\circ}$ lugar no número de artigos, e com um fator $\mathrm{H}$ mais alto do que o norte-americano (o fator $\mathrm{H}$ mede a quantidade ponderada pela qualidade dos trabalhos, sendo que essa é aferida pelo número de citações).

$\mathrm{O}$ fato de sermos o primeiro país do mundo em publicações na área ortodôntica não é tudo. A matriz de dados não incorpora o Dental Press Journal of Orthodontics publicado em inglês. Ou seja, nosso número de citações aumentará exponencialmente num futuro próximo. O jornal, quando ainda publicado com o nome Revista Dental Press 
de Ortodontia e Ortopedia Facial, teve um crescimento vertiginoso no período recente, como pode ser testemunhado no site da SCOPUS. Em certas configurações de busca, nosso jornal se encontra em $3^{\circ}$ lugar no cenário internacional. Mas isso é parte - apenas - do começo.

Impressionado com o crescimento da publicação brasileira na Odontologia, fiquei intrigado em relação ao cenário futuro. Mantidas as atuais taxas de expansão de publicação dos países, como estaremos em 5 anos? Para entender o cenário futuro, busquei o número de artigos publicados pelas principais nações ao longo de uma década, e realizei modelos de regressão linear - leia-se "previsão" - para projetar o ranking delas em 2016. A Figura 1 engloba todos os países analisados e tem, na área em amarelo, o futuro. O Brasil se tornará, em 2015, o principal produtor de conhecimento em Odontologia no mundo, ultrapassando os EUA. Observe nossa curva de ascensão.

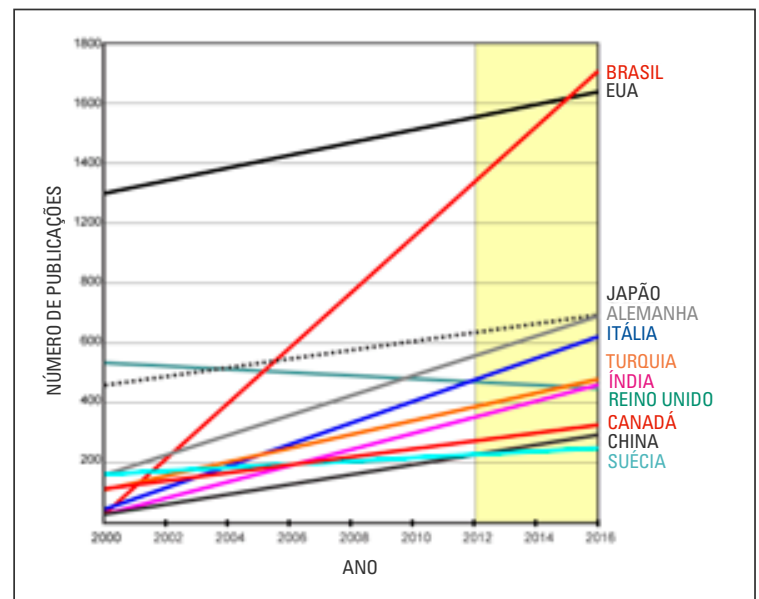

FIGURA 1 - A produção científica em Odontologia foi analisada por meio de modelos preditivos de regressão. Observe no gráfico o padrão de crescimento dos vários países. 0 Brasil se destaca e se tornará, em 2015, 0 principal produtor de conhecimento em Odontologia no mundo, ultrapassando os EUA.
A mudança de polaridade científica terá uma forte repercussão em nosso país. Nossas escolas terão que se adaptar para receber o estudante estrangeiro falante da língua inglesa. Não se espantem. Americanos e europeus se tornarão frequentadores assíduos de nossas universidades, invertendo a rota migratória estabelecida no século vinte. E essa cooperação será muito benéfica para todos.

Coordenadores de cursos no Brasil, preparem-se para esse cenário. Vocês receberão esses estudantes e desempenharão, frequentemente, o papel de líderes de grupos de pesquisa internacionais.

Boa leitura.

Jorge Faber

Editor-chefe

faber@dentalpress.com.br

\section{REFERÊNCIAS}

1. SClmago. (2007). SJR - SClmago Journal \& Country Rank. Retrieved March 23, 2011, from http://www.scimagojr.com. 